\title{
Physical disgust, germ aversion and antifat attitudes: the mediational effect of perceived controllability of weight
}

\author{
Alejandro Magallares* and Jose Francisco Morales \\ School of Psychology. Social Psychology Department, Universidad Nacional de Educacion a Distancia (UNED). Madrid (Spain).
}

\begin{abstract}
Título: Asco físico, aversión a los gérmenes y actitudes antiobesos: el efecto mediacional de la percepción de controlabilidad del peso.

Resumen: Las actitudes antiobesos se refieren a los estereotipos basados en el peso de las personas. Una posible explicación de las actitudes negativas hacia las personas obesas se basa en las reacciones emocionales suscitadas por el sobrepeso. En este estudio, realizado con 373 mujeres, se sugiere que el asco físico, la aversión a los gérmenes y la percepción de controlabilidad del peso juegan un papel central en la explicación de las diferencias individuales en lo que respecta a las actitudes antiobesos. Nuestros resultados mostraron una correlación positiva entre asco físico y aversión a los gérmenes. Adicionalmente, se halló una correlación positiva entre asco físico y percepción de controlabilidad del peso. También se encontró una relación positiva entre actitudes antiobesos, asco físico y aversión a los gérmenes. Finalmente, se halló que la percepción de controlabilidad del peso se relacionaba positivamente con las actitudes antiobesos. El análisis path realizado pone de manifiesto que la percepción de controlabilidad del peso media la relación existente entre el asco físico y las actitudes antiobesos. Finalmente, se discuten los resultados dentro del marco de la literatura sobre las actitudes antiobesos.

Palabras clave: asco físico, aversión a los gérmenes, percepción de controlabilidad del peso, actitudes antiobesos, análisis path.
\end{abstract}

\begin{abstract}
Antifat attitudes refer to stereotyping based on people's weight. A potential explanation for the strong negative attitudes toward obese individuals relates to people's emotional reactions. In this study, conducted with 373 female students, it is suggested that physical disgust, germ aversion and perceived controllability of weight play a central role in explaining the individual differences that exist in antifat attitudes. Our results showed a positive relationship between physical disgust and germ aversion. Additionally, it has been found a positive correlation between physical disgust and perceived controllability of weight. Furthermore, a positive relationship between antifat attitudes, physical disgust and germ aversion was found. Finally, perceived controllability of weight was positively related to antifat attitudes. The path analysis conducted showed the mediational effect of perceived controllability of weight in the relationship between physical disgust and antifat attitudes. Finally, it is discussed the results in the frame of antifat attitudes literature.
\end{abstract}

Key words: physical disgust; germ aversion; perceived controllability of weight; antifat attitudes; path analysis.

\section{Introduction}

An increasing number of people are facing the burden of obesity, which is defined as a Body Mass Index (BMI) of $\geq$ $30 \mathrm{~kg} / \mathrm{m}^{2}$ (Haslam \& James, 2005). Obesity is an important risk factor for other morbidities, such as type II diabetes, hypertension and coronary artery disease (Haslam \& James, 2005). The prevalence of obesity in the Western World almost doubled from $6.4 \%$ in 1980 to $12.0 \%$ in 2008 (Stevens et al., 2012). In Spain, the country where this study has been carried out, obesity has increased significantly in the last few years, reaching currently a prevalence rate of $23 \%$ (Gutierrez-Fisac et al., 2012).

Its steadily increasing prevalence rate in these societies has been paralleled by a strong social rejection and exclusion of obese people, who nowadays are exposed to a full array of discriminatory and stigmatizing experiences of many kinds in largely unfavorable societal contexts (see for a review: Puhl \& Heuer, 2009). Antifat attitudes refer to stereotyping based on people's weight (Crandall, 1994). Efforts to explain these negative attitudes have centered on ideological variables, but another potential explanation for the strong negative attitudes toward obese individuals relates to people's emotional reactions to people with weight problems. In this paper we will focus on the role that disgust and germ aversion may have in the existence of antifat attitudes.

* Dirección para correspondencia [Correspondence address]: Alejandro Magallares, Departamento de Psicología Social y de las Organizaciones, Facultad de Psicología UNED, C/ Juan del Rosal, 10, 28040 Madrid (España). E-mail: amagallares@psi.uned.es

\section{Disgust}

Disgust may be defined as a basic emotion that is elicited when people encounter a physical, sexual or moral contaminant which motivates distancing from the object (Oaten, Stevenson, \& Case, 2009).

It has been found that obesity elicits physical disgust for women but not for men (Lieberman, Tybur, \& Latner, 2012). Other authors have showed that physical disgust was a good predictor of negative attitudes toward obese individuals (O'Brien, et al., 2013). All these works suggest that physical disgust plays a central role in the explanation of antifat attitudes (Vartanian, Thomas, \& Vanman, 2013).

It is important to remark that physical disgust is also positively related to perceived vulnerability to disease (Tybur, Lieberman, \& Griskevicius, 2009). As a matter of fact, it has been suggested that disgust have evolved to perform the function of disease avoidance (Tybur et al., 2009).

\section{Germ aversion}

Perceived vulnerability to disease may be defined as the beliefs about personal susceptibility to the transmission of infectious diseases and the emotional discomfort associated to the potential disease transmission (Duncan, Schaller, \& Park, 2009). It has been showed that negative attitudes towards different stigmatized groups increased as a function of perceived vulnerability to disease (Navarrete \& Fessler, 2006). 
In relation to obesity, it has been found that perceived vulnerability to disease is related to the expression of antifat attitudes, especially the germ aversion factor of the perceived vulnerability to disease scale (Park, Schaller, \& Crandall, 2007). According to these authors, germ aversion, which may be defined as individuals' discomfort in situations that connote an increased likelihood for the transmission of pathogens, was a good predictor of negative attitudes toward obese individuals. Additionally, it has been found that germ aversion was related to discomfort toward individuals with weight problems and with a higher rejection to have physical contact with obese people (Park, Van Leeuwen, \& Chochorelou, 2013). These results are especially interesting because some authors argue that obesity may be spread through social ties (Christakis \& Fowler, 2007). As a matter of fact, it has been suggested a connection between obesity and abstract notions related to contagious diseases (Klaczynski, 2008).

\section{Perceived Controllability of Weight}

Besides the mentioned emotional variables, such as physical disgust and germ aversion, it has been found that the belief that weight is controllable figures prominently in the widespread prejudice and discrimination against obese people (Black, Sokol, \& Vartanian, 2014).

For example, some authors have showed that antifat attitudes may be reduced or exacerbated depending on the causal information provided about obesity to their partici- pants (O’Brien, Puhl, Latner \& Hunter, 2010). Recently, it has been found that one of the strongest predictor of antifat attitudes was controllability beliefs about obesity (Hansson \& Rasmussen, 2014).

It is important to remark that it has been found a positive correlation between perceived controllability of weight and physical disgust (Vartanian, 2010). Additionally, some authors suggest the mediational effect of controllability of weight in the explanation of antifat attitudes (Magallares, 2014).

Therefore, we have designed a cross-sectional study with a sample of women with physical disgust, germ aversion and perceived controllability of weight as the main predictors of antifat attitudes. According to the reviewed literature, it is expected that a positive relationship will be found between physical disgust and germ aversion. Additionally, we believe that we will found a positive correlation between physical disgust and perceived controllability of weight. In the third place, it is expected a positive relationship between antifat attitudes and physical disgust and germ aversion. On the fourth place, it is hypothesized that perceived controllability of weight will be positively related to antifat attitudes. Finally, we expected perceived controllability of weight to mediate the relationship physical disgust and antifat attitudes. Figure 1 presents the model that includes the set of hypotheses to be tested. It is important to remark that this model has not been tested before and it is based on the reviewed literature.

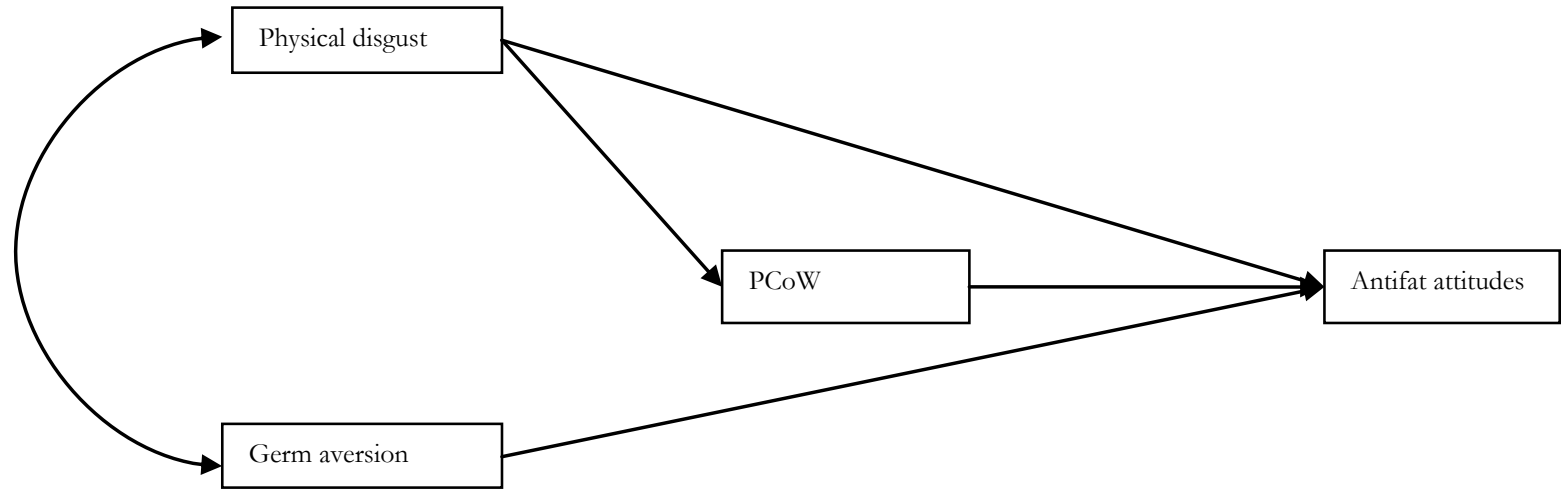

Note: Standardized estimations of the model.

The values of the arrows are the standardized regression coefficients $(\boldsymbol{\beta})$.

Figure 1: Proposed Model.

Note: PCoW: Perceived Controllability of Weight.

\section{Method}

\section{Sample}

Participants were 373 female students of the UNED (Spanish Open University) from 18 to 40 years (age: $M=$
$30.76, S D=9.42)$ who were enrolled in a psychology course and who received extra credit for their participation.

Participants' BMI was normal $(M=22.12, S D=3.97)$ according to the clinical standards (Haslam \& James, 2005). 


\section{Instruments}

To measure antifat attitudes the subscale of dislike of obese people of the Antifat Attitudes (AFA) scale was used (English version: Crandall, 1994; Spanish version: Magallares \&Morales, 2014). The subscale of dislike contains 7 items $(\alpha$ $=.74)$. An example is "I really don't like fat people much". The participants answered with a Likert scale from 1 (completely disagree) to 7 (completely agree). A score was computed by averaging the 7 items of the dislike subscale. Higher scores on this measure reflect greater dislike toward obese individuals.

To measure physical disgust the pathogen disgust subscale of The Disgust Domains Scale (TDDS) was used (English version: Tybur et al., 2009; Spanish version: Sandín, Santed, Chorot, Valiente, \& Pineda, 2015).). This subscale consists of 7 items $(\alpha=.72)$ rated on a 7 -point Likert-like scale ranging from not disgusting at all to extremely disgusting. Examples of pathogen disgust: "Standing close to a person who has body odor". A score was computed by averaging the 7 items of the pathogen disgust subscale. Higher scores on this measure reflect greater physical disgust.

To measure germ aversion the germ aversion subscale of the Perceived Vulnerability to Disease (PVD) was used (English version: Duncan et al., 2009; Spanish version: Magallares, Fuster-Ruiz de Apodaca, \& Morales, 2017). The germ aversion subscale $(\alpha=.64)$ contains 8 items in a Likert scale from 1 (completely disagree) to 7 (completely agree). An example of germ aversion) is "I prefer to clean my hands just after giving my hand to someone's hand". A score was computed by averaging the 8 items. Higher scores on germ aversion reflect greater individuals' discomfort in situations that connote an increased likelihood for the transmission of pathogens.

To measure perceived controllability of weight the subscale of willpower of the Antifat Attitudes (AFA) scale was used (English version: Crandall, 1994; Spanish version: Magallares \&Morales, 2014). The subscale of willpower $(\alpha=$ .75) contains 3 items. An example is "Fat people tend to be fat pretty much through their own fault". The participants answered with a Likert scale from 1 (completely disagree) to 7 (completely agree). A score was computed by averaging the 3 items of the willpower subscale. Higher scores on this measure reflect greater beliefs that obesity is under personal control.

\section{Procedure}

To recruit participants, students of all the Spanish territory were contacted trough the webpage of the university. Students were informed on the general purposes of the research and those who voluntarily wanted to participate completed an online questionnaire.

\section{Statistical analyses}

First of all, descriptive analyses were conducted. Means and standard deviations in all the variables of the study were estimated.

After that, Pearson's correlations were calculated among all the variables of the study.

Then, a path analysis with physical disgust and germ aversion as the independent variables, controllability of weight as the mediator variable, and antifat attitudes as the dependent variable, was conducted. We decided to introduce the manifest variables in the model following the recommendations of experts in the field (Coffman \& MacCallum, 2005). The Maximum Likelihood Estimation method was used with a level of significance of .05. To determine goodness of fit, the following indexes were employed: the chi square, the Normal Fit Index (NFI), the Non-normed Fit Index (NNFI), the Comparative Fit Index (CFI) and the Standardized Root Mean Square Residual (RMSEA). Additionally, the coefficient of determination or $\mathrm{R}^{2}$ was estimated. $\mathrm{R}^{2}$ provides information about the proportion of total variation explained by the model. According to experts, if the chi-square is not significant, the model is regarded as acceptable (Kline, 2011). Additionally, values higher than .95 on the NFI, NNFI, CFI indicate good fit (Kline, 2011). Finally, values lower than .05 on the RMSEA indicate good fit (Kline, 2011). Experts recommend the lower value of the $90 \%$ confidence interval should be a value near zero, or no worse than .05, and the upper value less than .08 (Kline, 2011). The width of the confidence interval is very informative about the precision in the estimate of the RMSEA.

The SPSS 19.0 was used to conduct the descriptive and correlational analyses. Finally to do the path analysis the AMOS 19.0 software was used.

\section{Results}

\section{Exploratory analysis}

First of all, means and standard deviations of all the variables of the study were calculated (see Table 1).

Table 1. Descriptives of the measures $(N=373)$.

\begin{tabular}{lcccc}
\hline Variables & Means & Standard deviations & Minimum & Maximum \\
\hline Physical disgust & 4.43 & 1.12 & 1.43 & 7 \\
Germ aversion & 3.65 & .78 & 1.75 & 6 \\
PCoW & 3.98 & 1.51 & 1 & 7 \\
Antifat attitudes & 1.85 & .91 & 1 & 6.71 \\
\hline
\end{tabular}

Note: PCoW: Perceived Controllability of Weight.

\section{Correlational analysis}

Once the means and standard deviations were estimated, Pearson's correlations of all the variables of the study were calculated. As it can be seen in Table 2, it has been found a positive relationship between physical disgust and germ 
aversion. Additionally, a positive correlation between physical disgust and perceived controllability of weight has been found. In the third place, a positive relationship between antifat attitudes and physical disgust and the germ aversion subscale has been found. Finally, perceived controllability of the weight was positively related to antifat attitudes.

Table 2. Correlations between measures.

\begin{tabular}{lllll}
\hline Correlations & 1 & 2 & 3 & 4 \\
\hline 1.Physical disgust & & & \\
2.Germ aversion & $.31^{* *}$ & & \\
3. PCoW & $.22^{* *}$ & $.11^{*}$ & \\
4.Antifat attitudes & $.19^{* *}$ & $.24^{* *}$ & $.25^{* *}$ & \\
\hline
\end{tabular}

$* p<.05 * * p<.01$

Note: PCoW: Perceived Controllability of Weight.

\section{Path analysis}

A path analysis was conducted with physical disgust, germ aversion, controllability of weight and antifat attitudes as the main variables (see Figure 1). The goodness of fit indices obtained for this model were satisfactory: $\chi^{2}(1)=.59$, $p=.44 ; \mathrm{NFI}=.99 ; \mathrm{NNFI}=.99 ; \mathrm{CFI}=.99 ; \mathrm{RMSEA}=.01$ $(.00, .05)$. The $\mathrm{R}^{2}$ of the dependent variable was .11 .

According to the model, germ aversion had a positive and direct effect on antifat attitudes. Physical disgust had an indirect effect on antifat attitudes trough perceived controllability of weight. Finally, it is showed a positive and direct effect of perceived controllability of weight on antifat attitudes.

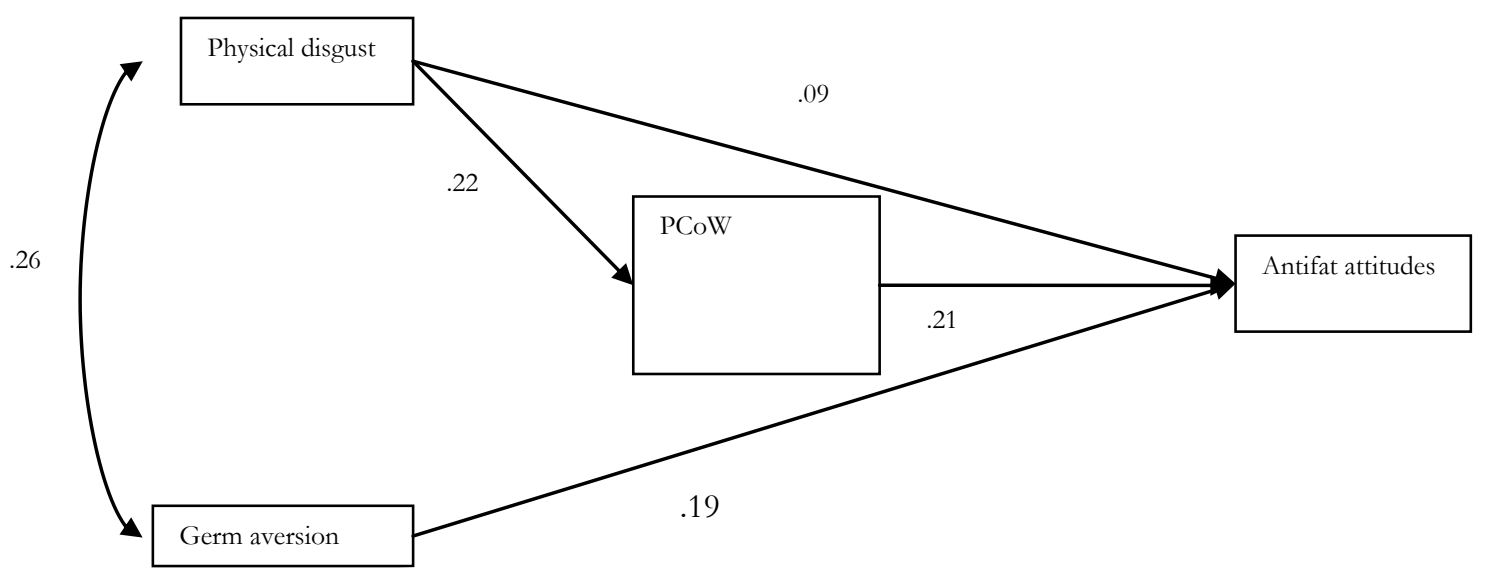

Note: Standardized estimations of the model.

The values of the arrows are the standardized regression coefficients $(\beta)$.

Figure 2: Path Analysis.

Note: PCoW: Perceived Controllability of Weight.

According to the results, it can be said that all the hypotheses of the study can be maintained. We have found positive and significant correlations between the variables of the study, such as physical disgust, germ aversion, perceived controllability of weight and antifat attitudes, as expected. Finally, the proposed model with perceived controllability of weight as a mediator variable has been tested with a path analysis and has been confirmed attending to the goodness of fit indices obtained.

\section{Discussion}

First of all, our results showed a positive relationship between physical disgust and germ aversion. This result is similar to the reviewed literature (Tybur et al., 2009). As it was pointed out in the introduction section, it has been suggested that disgust may have evolved to perform the function of disease avoidance (Tybur et al., 2009).
Additionally, it has been found a positive correlation between physical disgust and perceived controllability of weight. This result also confirms the reviewed literature (Vartanian, 2010). In other words, it seems that individuals that perceive that obesity is under personal control feel more disgust toward them. Recently, it has been found that when obese individuals put in effort to be healthy evoked less disgust in normal weight people (Black et al., 2014).

In the third place, as expected, a positive relationship between antifat attitudes and physical disgust (O’Brien, et al., 2013) and germ aversion (Park et al., 2007) has been found. Recent studies have showed, as our results did, that emotional factors are implicated in the explanation of the prejudice toward obese people. Our results suggest that the perception that obesity may be considered as a contagious disease is related to prejudice toward obese individuals (Klaczynski, 2008). We believe that the results found in the case of disgust have important implications for the understanding of antifat attitudes. The reviewed literature sug- 
gests that the inflexibility of disgust makes sense, from an evolutionary point of view, because it is better to make false alarms than to risk coming into contact with a disease carrier (Oaten et al., 2009). Therefore, this result might in part explain why antifat attitudes are so widespread (Crandall, 1994). Finally, it is important to remark that in the path analysis conducted the relationship between antifat attitudes and physical disgust was significant but no very high. This result suggests that the relationship between both variables is mediated by perceived controllability of weight.

In the fourth place, perceived controllability of the weight was positively related to antifat attitudes. This result also confirms the reviewed literature (Hansson \& Rasmussen, 2014). According to what we have found, it is suggested that the belief that obesity is under personal control is related to the prejudice toward obese individuals.

Finally, the path analysis conducted showed the mediational effect of perceived controllability of weight in the relationship between physical disgust and antifat attitudes (Magallares, 2014). This finding is a novelty in the field of the study of the causes of antifat attitudes.

The reason for the election of a sample composed only by women is based on the fact that it has been found that antifat attitudes are just related with physical disgust in the case of female participants (Vartanian et al., 2013). This result may be explained by the sociocultural differences about thinness internalization found between women and men. For example, it has been found that women, in contrast to men, prefer a slimmer body type (see for a meta-analysis: Cafri, Yamamiya, Brannick, \& Thompson, 2005). Given that disgust reactions tend to enforce social norms, this could also explain the link between physical disgust and antifat attitudes (Lieberman et al., 2012). However, it is important to remark that men tend to be more biased toward obese people than women (Magallares \& Morales, 2013).

Antifat attitudes have increased in the last years and some authors suggest that the current rate of weight discrimination is very similar to the rate of racial discrimination in the United States (Puhl \& Heuer, 2009). It is important to remark that some investigations have showed that antifat attitudes do not help obese people to have a healthy life and that the stigmatization of obese individuals has important implications for public health policies (see for a review: Sikorski et al., 2011). For these reasons, we believe that it is especially important to analyze which are the roots of the prejudice toward obese individuals. In other words, only through this theoretical knowledge we would be able to improve the programs that have the goal to change the image that obese people have. In a recent systematic review it was

\section{References}

Black, .M.J., Sokol, N., \& Vartanian, L.R. (2014). The effect of effort and weight controllability on perceptions of obese individuals. The Journal of Social Psychology, 154, 515-526. doi: 10.1080/00224545.2014.953025 shown different effective approaches to reducing antifat attitudes (Danielsdottira, O’Brien, \& Ciao, 2010). All of these methods to improve the image of obese people were based on theoretical studies analysing the origins of antifat attitudes.

The current study is subject to some limitations that deserve mention. First of all, it is a cross-sectional study. We believe that longitudinal studies would help to give a more accurate picture of the relationship between, physical disgust, germ aversion, perceived controllability of weight and antifat attitudes. In the second place, it is a correlational study. Furthermore, we believe that in addition to correlational approaches to the study of antifat attitudes, it would be interesting to run some kind of experimental studies, as shown by the line of work conducted in this field (see for example: O’Brien et al., 2010). The results of such studies would be very helpful in the development of intervention programs aimed at reducing negative attitudes toward people with weight problems. However, it is important to remark that a path analysis has been conducted to solve some of these problems. Third, the sample was only composed by psychology students. Future research should include different groups to see if the effects found in the study may be replicated with other collectives. Fourth, it is an online study. Some researchers have expressed concern about Webbased studies, but following experts recommendations these problems may be solved (Reips, 2007). Despite these limitations, the study provides new data with potential applications.

Finally, in addition to self-reported beliefs to assess antifat attitudes with explicit measures, it is important to remark that people also possess implicit or unconscious prejudices. For that reason, currently there is a great development of implicit association techniques to measure antifat attitudes. Future studies should address this issue.

This study presents some contributions with respect to the previous literature. First of all, to our knowledge, no other study has investigated the relationship between physical disgust, germ aversion, perceived controllability of weight and antifat attitudes at the same time. Additionally, in this study a path analysis has been conducted that helps to give an integrative view of the variables that are related to antifat attitudes. We believe that this article enriches and extends the field of antifat attitudes, as it provides a series of approaches that have not been taken into account before. Our focus on understanding how antifat attitudes manifest fills a gap in current literature on obesity and the emotional factors that foster prejudice and stigma.

Cafri, G., Yamamiya, Y., Brannick, M., \& Thompson, J.K. (2005). The influence of sociocultural factors on body image: a meta-analysis. Clinical Psychology: Science and Practice, 12, 421-433. doi: 10.1093/clipsy.bpi053 
Christakis, N. \& Fowler, J. (2007). The spread of obesity in a large social network over 32 Years. New England Journal of Medicine, 357, 370-379. doi: 10.1056/NEJMsa066082

Coffman, D. L. \& MacCallum, R. C. (2005). Using parcels to convert path analysis models into latent variable models. Multivariate Behavioral Research, 40, 235-259. doi: 10.1207/s15327906mbr4002_4

Crandall, C.S. (1994). Prejudice against fat people: Ideology and self-interest. Journal of Personality and Social Psychology, 66, 882-894. doi: 10.1037/00223514.66.5.882

Danielsdottira, S., O’Brien, .K.S., \& Ciao, A, (2010). Anti-Fat Prejudice Reduction: A Review of Published Studies. Obesity Facts, 3, 47-58 .doi: 10.1159/000277067

Duncan, L., Schaller, M. \& Park, J. (2009). Perceived vulnerability to disease: Development and validation of a 15 -item self-report instrument. Personality and Individual Differences, 47, 541-546. doi: 10.1016/j.paid.2009.05.001

Gutierrez-Fisac, J. L., Guallar-Castillon, P., Leon-Muñoz, L. M., Graciani, A., Banegas, J. R., \& Rodriguez-Artalejo, F. (2012). Prevalence of general and abdominal obesity in the adult population of Spain, 2008-2010: The ENRICA study. Obesity Review, 13, 388-392. doi: j.1467789X.2011.00964.x

Hansson, L.M. \& Rasmussen, F. (2014): Attitudes towards obesity in the Swedish general population: The role of one's own body size, weight satisfaction, and controllability beliefs about obesity. Body Image, 11, 4350. doi: 10.1016/j.bodyim.2013.10.004

Haslam, D. W. \& James, P. T. (2005). Obesity. Lancet, 366, 1197-1209. doi: 10.1016/S0140-6736(05)67483-1

Klaczynski, P. (2008). There's something about obesity: Culture, contagion, rationality, and children's responses to drinks "created" by obese children. Journal of Experimental Child Psychology, 99, 58-74. doi: 10.1016/j.jecp.2007.08.005

Kline, R. (2011). Principles and practice of Structural Equation Modeling. Nueva York: Guilford Press.

Lieberman, D.L., Tybur, J.M., \& Latner, J.D. (2012). Disgust sensitivity, obesity stigma, and gender: Contamination psychology predicts weight bias for women, not men. Obesity, 20, 1803-1814. doi:10.1038/oby.2011.247

Magallares, A. (2014). Right Wing Autoritharism, Social Dominance Orientation, controllability of the weight and their relationship with antifat attitudes. Universitas Psychologica, 13, 15-23. doi: 10.11144/Javeriana.UPSY13-2.rwas

Magallares, A., Fuster-Ruiz de Apodaca, M.J. \& Morales, J.F. (2017). Psychometric properties and criterion validity of the Perceived Vulnerability to Disease Scale (PVD) in Spanish population. Revista de Psicologia Social, 32.

Magallares, A. \& Morales, J.F. (2013). Gender differences in antifat attitudes. Revista de Psicologia Social, 28, 113-119. doi: $10.1174 / 021347413804756014$

Magallares, A. \& Morales, J.F. (2014). Adaptación al castellano de la Escala de Actitud Antiobesos [Spanish adaptation of the Antifat Attitudes Scale]. Revista de Psicologia Social, 29, 563-588. doi: 10.1080/02134748.2014.972707
Navarrete, C. D., \& Fessler, D. M. T. (2006). Disease avoidance and ethnocentrism: The effects of disease vulnerability and disgust sensitivity on intergroup attitudes. Evolution and Human Behavior, 27, 270-282. doi: 10.1016/j.evolhumbehav.2005.12.001

Oaten, M., Stevenson, R. J., \& Case, T. I. (2009). Disgust as a diseaseavoidance mechanism. Psychological Bulletin, 135,303-321. doi: $10.1037 / \mathrm{a} 0014823$

O’Brien, K.S., Daníelsdóttir, S., Ólafsson, R.P., Hansdóttir, I., Fridjónsdót tir, T.G., \& Jónsdóttir, H. (2013). The relationship between physical appearance concerns, disgust, and anti-fat prejudice. Body Image, 10 619-623. doi: 10.1016/j.bodyim.2013.07.012

O’Brien, K., Puhl, R., Latner, J., Mir, A., \& Hunter, J. (2010). Reducing antifat prejudice in preservice health students: A randomized trial. Obesity, 18, 2138-2144. doi: 10.1038/oby.2010.79

Park, J., Schaller, M. \& Crandall, C. (2007). Pathogen-avoidance mechanisms and the stigmatization of obese people. Evolution and Human Behavior, 28 , 410-414. doi: 10.1016/j.evolhumbehav.2007.05.008

Park, J., Van Leeuwen, F., \& Chochorelou, Y. (2013). Disease-avoidance processes and stigmatization: Cues of substandard health arouse heightened discomfort with physical contact. Journal of Social Psychology, 153, 212-228. doi: 10.1080/00224545.2012.721812

Puhl, R. M. \& Heuer, C. A. (2009). The stigma of obesity: A review and update. Obesity, 17, 941-964. doi: 10.1038/oby.2008.636

Reips, U.D. (2007). The methodology of Internet-based experiments. In A. Joinson, K. McKenna, T. Postmes, \& U.-D. Reips (Eds.), The Oxford Handbook of Internet Psychology (pp. 373-390). Oxford: Oxford University Press.

Sandín, B., Santed, M.A., Chorot, P., Valiente, R., \& Pineda, D. (2015). Spanish version of the Three Domains Disgust Scale (TDDS). Paper presented at the 45th European Association for Behavioural and Cognitive Therapies. Jerusalem, Israel.

Sikorski, C., Luppa, M., Kaiser, M., Glaesmer, H., Schomerus, G., ... \& Riedel-Heller, S. (2011). The stigma of obesity in the general public and its implications for public health - a systematic review. BMC Public Health, 11, 661. doi:10.1186/1471-2458-11-661

Stevens, G., Singh, G., Lu, Y., Danaei, G., Lin, J., ... \& the Global Burden of Metabolic Risk Factors of Chronic Diseases Collaborating Group (Body Mass Index) (2012). National, regional, and global trends in adult overweight and obesity prevalences. Population Health Metrics, 10, 22. doi:10.1186/1478-7954-10-22

Tybur, J.M., Lieberman, D., \& Griskevicius, V. (2009). Microbes, mating, and morality: Individual differences in Three Functional Domains of Disgust. Journal of Personality and Social Psychology, 97, 103-122. doi: $10.1037 / \mathrm{a} 0015474$

Vartanian, L.R. (2010). Disgust and perceived control in attitudes toward obese people. International Journal of Obesity, 34, 1302-1307. doi:10.1038/ijo.2010.45

Vartanian, L.R., Thomas, M.A., \& Vanman, E.J. (2013). Disgust, contempt, and anger and the stereotypes of obese people. Eating \& Weight Disor ders, 18, 377-382. doi: 10.1007/s40519-013-0067-2

(Article received: 07-04-2015; revised: 10-06-2015; accepted: 28-06-2015) 